\title{
Arahan Penyediaan RTH Publik untuk Menyerap Emisi Gas CO2 Kendaraan Bermotor di Kecamatan Kebayoran Baru, Jakarta Selatan (Studi Kasus: Kawasan Perdagangan dan Jasa Mayestik - Barito)
}

\author{
Nadira Dwiputri Lase dan Haryo Sulistyarso \\ Departemen Perencanaan Wilayah dan Kota, Fakultas Teknik Sipil dan Perencanaan, Institut \\ Teknologi Sepuluh Nopember (ITS)
}

e-mail: haryo.its@gmail.com

\begin{abstract}
Abstrak-Kawasan perdagangan dan jasa Mayestik - Barito di Kecamatan Kebayoran Baru, Jakarta Selatan merupakan kawasan yang ramai akan pengunjung. Belum terintegrasinya transportasi umum di Jakarta memicu penggunaan kendaraan motor pribadi yang tinggi sehingga emisi gas, salah satunya gas $\mathrm{CO}_{2}$, yang dikeluarkan juga tinggi. Penelitian ini bertujuan untuk menyediakan arahan RTH publik lahan horizontal untuk mereduksi gas $\mathrm{CO}_{2}$ kendaraan bermotor di kawasan perdagangan dan jasa Mayestik - Barito. Untuk mencapai tujuan tersebut terdapat beberapa proses, yaitu perhitungan kendaraan bermotor, perhitungan emisi gas $\mathrm{CO}_{2}$ menggunakan software Mobilev 3.0, melakukan perhitungan matematis kebutuhan RTH tambahan untuk menyerap emisi, dan menyediakan arahan. Teknink analisis untuk menentukan arahannya secara deskriptif dengan menambahkan dan mengoptimalkan lahan potensial dan mempertahankan RTH eksisting. Hasil yang diperoleh adalah emisi yang dikeluarkan di kawasan studi sebesar 4,729 ton/tahun, dimana untuk menyerap keseluruhan emisi membutuhkan 2.8 Ha. Akan tetapi, untuk mendekati angka 2.8 Ha dapat menambahkan lahan potensial RTH di Jl. Barito seluas 1 Ha dan jalur hijau di Jl. Kyai Maja seluas 1.6 Ha, sehingga emisi yang belum tereduksi sangat minim. Sedangkan pengoptimalan lahan RTH dapat dilakukan dengan cara pemilihan vegetasi pereduksi gas $\mathrm{CO}_{2}$.
\end{abstract}

Kata Kunci: Ruang Terbuka Hijau, Emisi, $\mathrm{CO}_{2}$, Kendaraan Bermotor.

\section{PENDAHULUAN}

$\mathrm{R}$ TH atau Ruang Terbuka Hijau merupakan area memanjang atau mengelompok yang ditumbuhi tanaman baik alami maupun buatan yang memiliki fungsi tertentu. Keberadaan RTH memiliki manfaat langsung seperti terciptanya estetika yang baik dan adanya icon kota dan manfaat tidak langsung seperti pembersih udara, pemeliharaan akan kelangsungan persediaan air tanah, pelestarian fungsi lingkungan segala isi flora dan fauna yang ada [1]. Mengetahui pengertian tersebut, secara implisit di kawasan perkotaan RTH sangat diperlukan untuk membersihkan udara yang tercemar akibat aktivitas perkotaan.

Berdasarkan pengertian singkat mengenai RTH, beberapa penelitian maupun artikel mengatakan bahwa RTH dapat meningkatkan kualitas lingkungan dan mencegah terjadinya pencemaran udara oleh kendaraan bermotor dengan cara menyerap polutan berdasarkan fungsi utama dari RTH di kawasan perkotaan. Hal tersebut didukung oleh penelitian yang telah dilakukan Purnomohadi pada tahun 1994 yang mengatakan bahwa keberadaan RTH dapat menyerap zat polutan terdapat korelasi yang nyata [2]. Zat polutan yang ada sebisa mungkin harus diminimalisir karena dapat menyebabkan penyakit seperti infeksi saluran pernafasan atas, paru-paru menjadi rusak, hipertensi, jantung, kanker dan lain sebagainya [3].

Menurut penelitian Wardhana pada tahun 1984, juga mengatakan bahwa banyak jenis gas yang dikeluarkan oleh kendaraan bermotor, akan tetapi dalam prosentasenya emisi gas $\mathrm{CO}_{2}$ memiliki kedudukan yang tinggi apabila dibandingkan dengan gas yang lain yaitu sebesar 70,53\% [3]. Tinggi rendahnya kadar emisi dipengaruhi oleh jumlah kendaraan bermotor yang juga dipengaruhi oleh jenis kegiatan yang ada disana, salah satunya perdagangan dan jasa karena kegiatan perdagangan dan jasa mempengaruhi banyaknya kendaraan bermotor di koridor jalan karena memicu pengunjung untuk datang [4].

Perdagangan dan Jasa pada umumnya ditemukan di kotakota besar seperti Jakarta. Jakarta adalah Ibukota Indonesia yang pembangunannya tergolong lebih maju dari kota-kota lainnya. Pertumbuhan perdagangan dan jasa setiap tahunnya terus meningkat, seperti di Kebayoran Baru, Jakarta Selatan, yang sekarang didominasi oleh kegiatan perdagangan dan jasa [5]. Berdasarkan Perda DKI Jakarta No. 1 Tahun 2012 tentang Rencana Tata Ruang Wilayah 2030, Kebayoran Baru memiliki pusat kegiatan paling banyak, salah satunya perdagangan dan jasa yang banyak menarik pengunjung yaitu di kawasan Pasar Mayestik.

Kawasan Pasar Mayestik merupakan salah satu kawasan perdagangan dan jasa yang memiliki lokasi strategis, dan dikelilingi oleh banyak jenis perdagangan dan jasa seperti tempat makan berbentuk restoran, hingga kaki lima yang banyak mengundang banyak pengunjung yang menyebabkan padatnya lalu lintas, dimana total jumlah kendaraan paling banyak di kawasan Pasar Mayestik pada waktu peak hour dapat mencapai 19,545 unit kendaraan [6]. Hal ini dikarenakan kondisi transportasi di Jakarta yang 
belum adanya transportasi umum yang terintegrasi, sehingga memicu masyarakat di Jakarta menggunakan kendaraan pribadi yang tentunya berpotensi sebagai sumber polusi udara yang cukup tinggi sehingga emisi gas kendaraan bermotor otomatis menjadi tinggi.

Upaya pencegahan terjadinya emisi gas $\mathrm{CO}_{2}$ kendaraan bermotor yang berlebihan adalah dengan menyediakan RTH untuk menyerap emisi tersebut agar tidak menimbulkan penyakit dan merusak lingkungan, karena gas $\mathrm{CO}_{2}$ digunakan sebagai proses fotosintesis untuk menghasilkan oksigen sehingga dapat membersihkan udara dari emisi yang dihasilkan oleh kendaraan bermotor. Selain itu, Dinas Pertamanan DKI Jakarta sedang mengupayakan pewujudan $30 \%$ RTH dari luas wilayah yang ditimbang dari beberapa aspek, seperti kebutuhan oksigen dan kebutuhan untuk menyerap $\mathrm{CO}_{2}$, dimana $20 \%$ meliputi RTH publik dan $10 \%$ RTH privat [7].

Mengetahui fakta yang telah diketahui, peran RTH di dalam perkotaan sangat penting untuk menjaga kualitas udara dengan cara menyerap emisi gas $\mathrm{CO}_{2}$ untuk menghasilkan oksigen $\left(\mathrm{O}_{2}\right)$ agar masyarakat perkotaan dapat hidup sehat, terutama di kawasan perkotaan yang banyak ditumbuhi perdagangan dan jasa, seperti di Kawasan Pasar Mayestik - Jl. Barito, serta belum adanya transportasi yang terintegrasi dengan baik. Sehingga, penggunaan kendaraan bermotor pribadi dapat dikatakan tinggi. Maka dari itu, perlu adanya arahan penyediaan RTH berdasarkan emisi gas $\mathrm{CO}_{2}$ kendaraan bermotor untuk meminimalisir emisi gas $\mathrm{CO}_{2}$ yang dikeluarkan.

\section{METODE PENELITIAN}

\section{A. Jenis dan Pendekatan Penelitian}

Pendekatan penelitian yang digunakan adalah penelitian rasionalistik, dimana penelitian menggunakan dasar teori dan keadaan eksisting. Jenis penelitian yang digunakan adalah penelitian applied research eksplorasi yang memiliki tujuan memperbaiki suatu keadaan eksisting. [8]

\section{B. Variabel Penelitian}

Variabel yang digunakan untuk menghitung jumlah kendaraan bermotor adalah jumlah kendaraan bermotor sesuai jenisnya dan lama waktu pengamatan. Untuk jumlah emisi gas $\mathrm{CO}_{2}$ kendaraan bermotor menggunakan variabel arus lalu lintas (hasil sasaran 1), faktor emisi, konsumsi/jenis bahan bakar, jumlah lajur, arah jalan, kategori jalan, panjang jalan, dan kemiringan jalan.

Variabel yang digunakan untuk menghitung kebutuhan luas RTH publik adalah jumlah emisi gas $\mathrm{CO}_{2}$ kendaraan, luas taman (softscape) dan nilai daya serap $\mathrm{CO}_{2}$ pohon. Sedangkan variabel arahan penyediaan menggunakan luas RTH yang dibutuhkan.

\section{Jumlah kendaraan bermotor di kawasan studi (traffic counting)}

Perhitungan jumlah kendaraan bermotor dilakukan di beberapa titik di ruas jalan kolektor dan lokal yaitu Jl. Bumi, Jl. Leuser, Jl. Kyai Maja, Jl. Barito, Jl. Gandaria Tengah III - Melawai, dan Jl. Ahmad Dahlan Kby. pada waktu-waktu tertentu secara deskriptif dengan metode kuantitatif. Hasil dari perhitungan jumlah kendaraan bermotor di kawasan studi disajikan secara kuantitatif dengan tabel dan akan dijelaskan secara deskriptif.

\section{Jumlah emisi gas $\mathrm{CO}_{2}$ kendaraan bermotor}

Perhitungan ini dilakukan menggunakan bantuan software Mobilev 3.0 yang dikeluarkan oleh Tim Inventarisasi Emisi 2013 dengan mengkonversikan hasil ke satuan ton/tahun.

\section{E. Kebutuhan luas RTH publik}

Langkah yang dilakukan untuk menghitung kebutuhan luas RTH adalah mengidentifikasi softscape dari setiap taman di kawasan studi. Selanjutnya, menghitung daya serap eksisting softscape dengan mengkalikan luas softscape keseluruhan dengan nilai daya serap pohon ton/ha/tahun (569.07). Kemudian hasil kemampuan daya serap dikurangi oleh hasil perhitungan emisi eksisting yang dinamakan emisi sisa. Lalu, emisi sisa tersebut dibagi dengan nilai daya serap pohon untuk menentukan kebutuhan luas dalam satuan ha.

\section{F. Arahan penyediaan RTH publik}

Arahan penyediaan dilihat dari kondisi eksisting, masterplan, lingkungan, peraturan pemerintah, dan sebagainya yang nantinya akan diambil keputusannya secara deskriptif kualitatif seperti taman kota, hutan kota, dan jalur hijau.

\section{HASIL DAN DISKUSI}

\section{A. Jumlah Kendaraan Bermotor}

Perhitungan jumlah kendaraan bermotor telah dilakukan pada waktu sibuk yaitu pada pukul 16.00 WIB - 18.00 WIB. Jumlah kendaraan paling banyak ditemukan di Jl. Kyai Maja yaitu sebanyak 19,193 unit. Sedangkan jumlah kendaraan paling sedikit ditemukan di Jl. Leuser yaitu sebanyak 7,265 unit. Untuk total jumlah kendaraan keseluruhan sebanyak 76,344 unit.

\section{B. Jumlah Emisi Gas CO2 Kendaraan Bermotor}

Jumlah emisi gas $\mathrm{CO}_{2}$ yang dihitung menggunakan software Mobilev 3.0 masih menggunakan satuan gram $/ \mathrm{km}^{*}$ jam sebesar 1,485,836. Angka tersebut masih harus dikonversikan ke ton/tahun sehingga emisi $\mathrm{CO}_{2}$ yang dikeluarkan kendaraan bermotor sebesar 4,728 ton/tahun.

Tabel 1.

Emisi Gas CO2 yang Dikeluarkan Kendaraan Bermotor di Kawasan Studi

\begin{tabular}{|c|c|c|c|}
\hline $\begin{array}{l}\text { No. } \\
\text { (1) }\end{array}$ & $\begin{array}{c}\text { Nama Jalan } \\
\text { (2) }\end{array}$ & $\begin{array}{c}\text { Jumlah Emisi } \\
\text { (kg/hari) } \\
(3)\end{array}$ & $\begin{array}{c}\text { Jumlah Emisi } \\
\text { (ton/tahun) } \\
(4)\end{array}$ \\
\hline 1. & J1. Bumi & 222 & 81 \\
\hline 2. & Jl. Leuser & 206 & 75 \\
\hline 3. & Jl. Kyai Maja & 11,156 & 4,072 \\
\hline 4. & Jl. Ahmad Dahlan Kby. & 406 & 148 \\
\hline 5. & $\begin{array}{l}\text { J1. Melawai - Gandaria } \\
\text { Tengah III }\end{array}$ & 489 & 179 \\
\hline 6. & Jl. Barito I & 478 & 174 \\
\hline & Total & 12,957 & 4,729 \\
\hline
\end{tabular}

Sumber: Hasil Analisis, 2017

\section{Kebutuhan RTH Publik untuk Menyerap Emisi Gas CO2}

Setelah mengetahui emisi gas $\mathrm{CO}_{2}$ kendaraan bermotor yang dikeluarkan di kawasan studi, dilakukan perhitungan kemampuan daya serap RTH eksisting untuk menyerap emisi gas $\mathrm{CO}_{2}$ yaitu sebesar 3,126 ton/tahun. Maka, emisi sisa yang belum terserap adalah sebesar 1,602 ton/tahun. Setelah itu, untuk mengetahui kebutuhan RTH Publik, emisi sisa dibagi dengan nilai daya serap $\mathrm{CO}_{2}$ pohon. Hasil yang diperoleh adalah masih membutuhkan $2.8 \mathrm{Ha}$. 


\section{Arahan Penyediaan RTH Publik}

Dalam merumuskan arahan penyediaan untuk mendekati $2.8 \mathrm{Ha}$, diperoleh arahan penyediaan RTH publik dengan cara penambahan lahan potensial dan jalur hijau, pengoptimalan lahan potensial, serta mempertahankan RTH eksisting, sehingga mampu menambah $2.6 \mathrm{Ha}$ lahan horizontal yang tentunya didukung dengan pemilihan vegetasi yang tepat. Sebelum merumuskan arahan, dilakukan interpolasi emisi agar pencarian dan peletakkan lahan potensial dan jalur hijau dapat dimanfaatkan dengan baik.
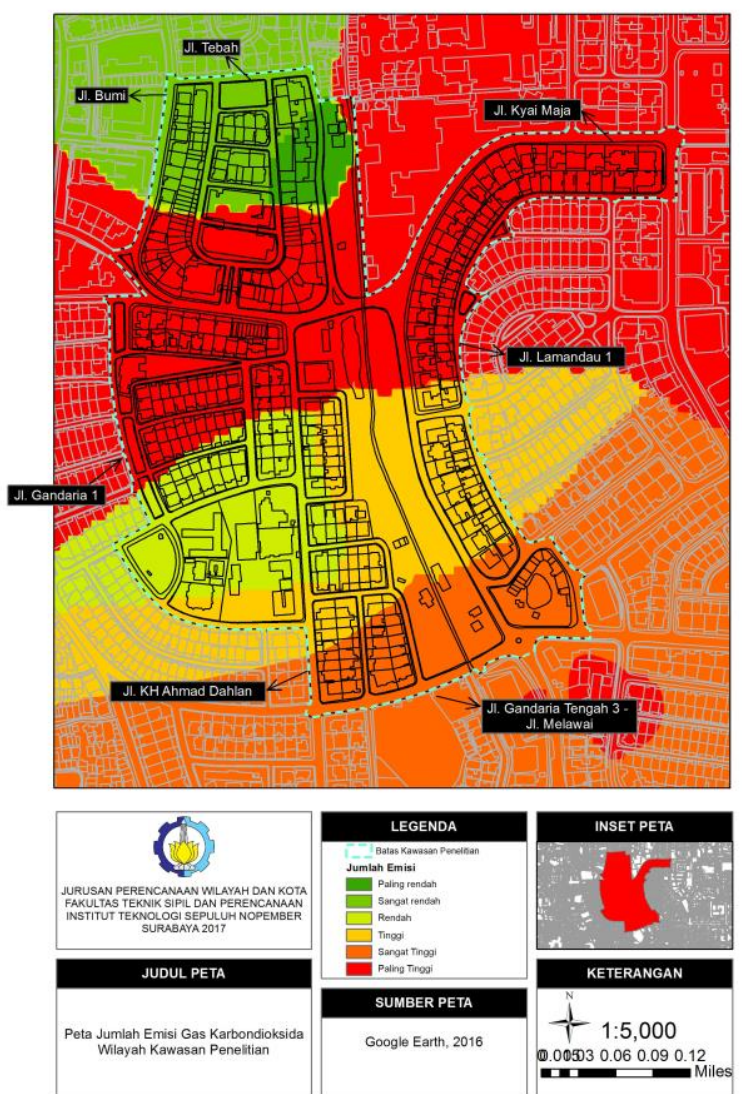

Gambar 1. Peta Jumlah Emisi Gas Karbondioksida Wilayah Kawasan Penelitian.

Pada peta tersebut terlihat bahwa gradasi dari warna hijau hingga merah, dimana warna hijau merupakan emisi paling rendah dan warna merah merupakan emisi paling tinggi dengan keterangan sebagai berikut.

Tabel 2.

Keterangan Peta Interpolasi

\begin{tabular}{|c|c|c|}
\hline No. & "Warna & "Nilai \\
\hline 1 & & $<75$ ton/tahun \\
\hline 2 & & $75-81$ ton/tahun \\
\hline 3 & & $81-148$ ton/tahun \\
\hline 4 & & $148-162$ ton/tahun \\
\hline 5 & & $162-179$ ton/tahun \\
\hline 6 & & $179-4,072$ ton/tahun \\
\hline
\end{tabular}

Sumber: Hasil Analisis, 2017

- Penambahan lahan potensial dan jalur hijau

Lahan Potensial RTH I merupakan lahan yang terletak di Jl. Leuser seluas $1 \mathrm{Ha}$. Lahan ini dapat dijadikan hutan kota karena pertimbangan lokasi dan lingkungan di kawasan studi. Apabila lahan ini dijadikan hutan kota, kebutuhan 2.8 Ha dapat berkurang menjadi $1.7 \mathrm{Ha}$ dan mampu mereduksi hampir 50\% dari emisi gas kendaraan bermotor dengan ketentuan minimal $90 \%$ dari lahan merupakan lahan yang ditumbuhi tanaman [1]. Selain itu, dalam suatu kawasan diperlukan suatu hutan kota untuk menjaga iklim dan menjadi siklus udara.

Jalur hijau yang akan dibuat untuk penyerapan emisi gas $\mathrm{CO}_{2}$ sisa terletak di Jl. Kyai Maja seluas 1.6 Ha. Maka, pemanfaatan jalur hijau ini tentunya dapat mereduksi $\mathrm{CO}_{2}$ lebih. Selain itu, adanya jalur hijau dengan penanaman tumbuhan yang tepat dapat menjadi salah satu penyerap polutan yang paling efektif.

- Pengoptimalan lahan potensial

Lahan potensial RTH II ditemukan di Jl. Barito yang merupakan Taman Langsat. Berdasarkan hasil analisis perhitungan komposisi benda mati dan benda hidup menggunakan pendekatan Google Earth, angka prosentasi benda mati hanya $7 \%$ di lahan tersebut. Akan tetapi, menurut Permen PU tahun 2008 tentang Penyediaan dan Pemanfaatan Ruang Terbuka Hijau Di Kawasan Perkotaan, apabila taman kota mau dijadikan lapangan hijau, memiliki kriteria 80 - 90\% lahan dijadikan benda hidup dan sisanya dapat dibangun fasilitas olahraga maupun rekreasi.

- Mempertahankan RTH eksisting

Dalam merumuskan arahan penyediaan, mempertahankan keberadaan RTH eksisting sangat diperlukan. Hal tersebut dikarenakan untuk menyerap emisi gas $\mathrm{CO}_{2}$ masih diperlukan RTH yang banyak, yaitu sebesar 2.8 Ha.

- Rekomendasi vegetasi

Penyerapan emisi akan lebih optimal apabila adanya kombinasi antara pohon dengan semak maupun perdu [10]. Selain itu, kriteria vegetasi yang tepat untuk menyerap emisi $\mathrm{CO}_{2}$ adalah tanaman yang memiliki tajuk masif, berdaun tipis dan lebar, bertrikoma/berbulu dan bergerigi.

Pemilihan vegetasi yang tepat disesuaikan dengan peruntukannya, seperti untuk taman kota tutupan pohon yang tepat seperti Ki Hujan (Samanea saman), Akasia (Accacia mangium), Beringin (Ficus benjamina), dan Kupukupu (Bauhinia purpurea). Sedangkan untuk jalur hijau yang tepat seperti Angsana (Pterocarpus indicus), Oleander (Nerium oleander), dan Bogenvil (Bougainvillea sp).

\section{KESIMPULAN DAN SARAN}

Berdasarkan keseluruhan proses analisis yang telah dilakukan dengan tujuan menyediakan arahan RTH untuk menyerap emisi gas $\mathrm{CO}_{2}$ kendaraan bermotor, berikut adalah beberapa poin yang dapat disimpulkan:

1. Jumlah kendaraan di kawasan studi adalah 76,344 unit kendaraan. Kendaraan tersebut terbagi menjadi 4 (empat) jenis yaitu mobil, motor, bus, truk kecil, dan bajaj. Kendaraan terbanyak yang melalui kawasan studi terdapat di Jl. Kyai Maja yaitu sebanyak 19,193 unit. Sedangkan yang paling sedikit terdapat di Jl. Leuser yaitu sebanyak 7,265 unit.

2. Jumlah emisi gas $\mathrm{CO}_{2}$ kendaraan yang dikeluarkan bermotor sebanyak 4,729 ton/tahun. Jumlah emisi paling banyak terletak di Jl. Kyai Maja yaitu sebanyak 4,072 ton/tahun. Hal tersebut dikarenakan jumlah kendaraan yang ada dan J1. Kyai Maja merupakan satu-satunya jalan kolektor di kawasan studi

3. Emisi gas $\mathrm{CO}_{2}$ kendaraan bermotor yang belum terserap adalah sebesar 1,603 ton/tahun. Hal tersebut 
masih membutuhkan 2.8 Ha untuk mereduksi emisi gas $\mathrm{CO}_{2}$ kendaraan.

4. Arahan untuk mencapai $2.8 \mathrm{Ha}$ yang belum tersedia adalah dengan mencari lahan potensial RTH dan jalur hijau, mengoptimalkan lahan potensial, dan mempertahankan keberadaan RTH eksisting dan mengoptimalkannya, seperti pemilihan vegetasi yang dikombinasikan antara pohon, perdu, dan semak.

5. Saran yang bisa dilakukan adalah melakukan kajian lebih lanjut mengenai pengoptimalan taman untuk menyerap emisi gas $\mathrm{CO} 2$ dan pengkajian lahan vertikal yang tepat di Indonesia.

\section{DAFTAR PUSTAKA}

[1] J. P. Ruang, Pedoman Penyediaan dan Pemanfaatan Ruang Terbuka Hijau di Kawasan Perkotaan. Jakarta: Menteri
Pekerjaan Umum, 2008.

[2] M. S. Dewi, Studi Kebutuhan Ruang Terbuka Hijau Untuk Menurunkan Tingkat Pencemaran Udara Oleh Emisi Kendaraan Bermotor Di Kota Tangerang. 2008.

[3] Sugiarti, Gas Pencemar Udara Dan Pengaruhnya Bagi Kesehatan Manusia. 2009.

[4] F. F. Anugra, "In Penanganan Kemacetan Lalu Lintas di Koridor Jalan Kramat Gantung, Surabaya,” Institut Teknologi Sepuluh Nopember, 2014.

[5] D. P. Sugianto, "In Identifikasi Lanskap Kota Taman Kebayoran Baru Sebagai Identitas Kotamadya Jakarta Selatan," Institut Pertanian Bogor, 2010.

[6] Universitas Indonesia, Penyusunan Masterplan Ruang Terbuka Hijau DKI Jakarta. Jakarta: Dinas Kehutanan dan Pertamanan DKI Jakarta, 2015.

[7] M. Dr. Ir. Masyhuri, M., \& Drs. M. Zainuddin, In Metodologi Penelitian Pendekatan Praktis dan Aplikatif. Bandung: PT Refika Aditama, 2008.

[8] T. K. Emisi, Panduan Mobilev 3.0. 2013. 